
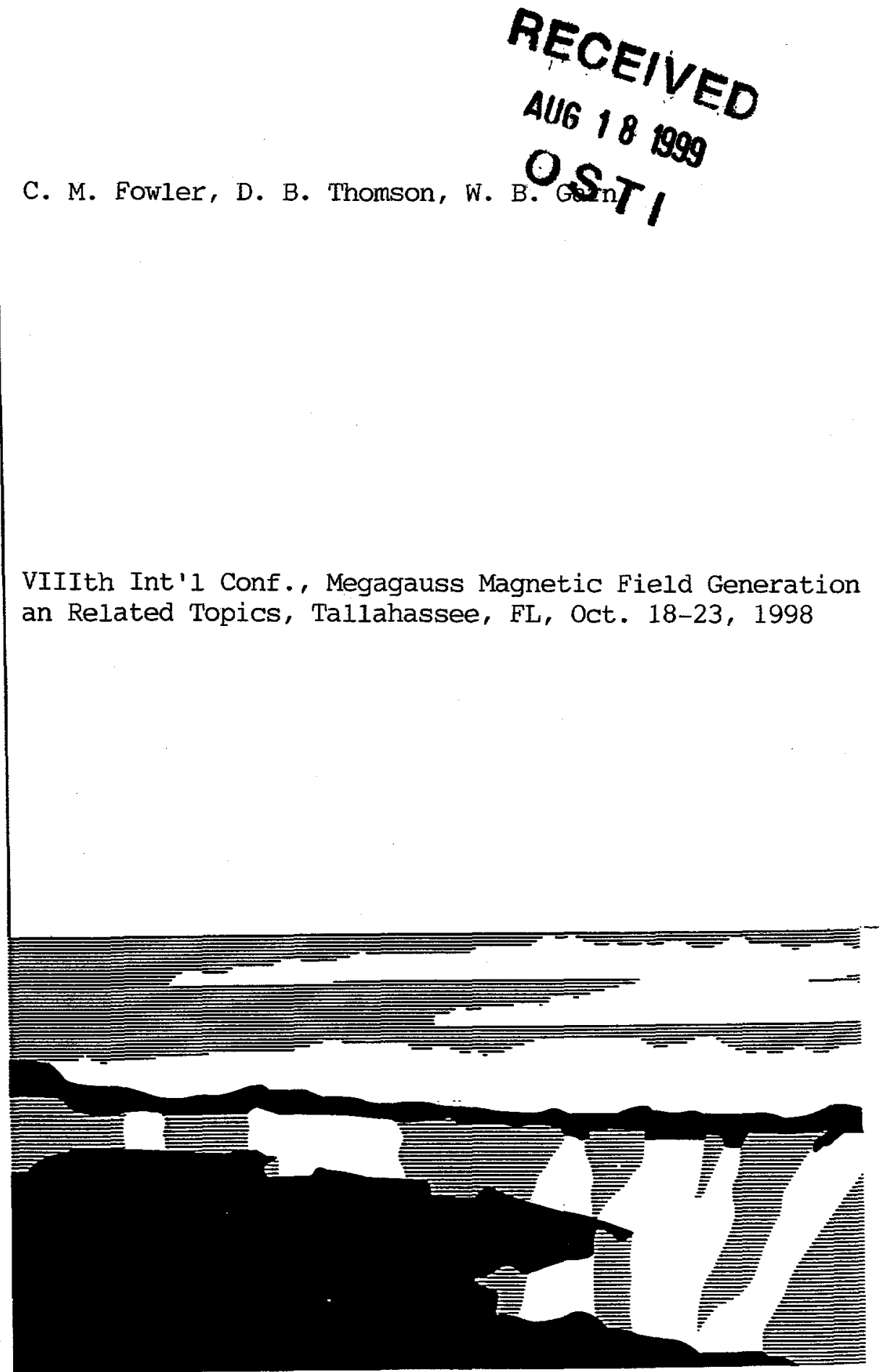

Los Alamos National Laboratory, an affimative action/equal opportunity employer, is operated by the University of Callfomia for the

U.S. Department of Energy under contract W-7405-ENG-36. By acceptance of this article, the publlsher recognizes that the U.S.

Government retains a nonexclusive, royalty-free license to publish or reproduce the published form of this contribution, or to allow

others to do so, for U.S. Govemment purposes. Los Alamos National Laboratory requests that the pubilisher identify this article

as work performed under the ausplces of the U.S. Department of Energy. The Los Alamos National Laboratory strongly supports

academic freedom and a researcher's ifght to publish; as an institution. however, the Laboratory does not endorse the viewpolint

of a publication or guarantee its technical correctness. 


\section{DISCLAIMER}

This report was prepared as an account of work sponsored by an agency of the United States Government. Neither the United States Government nor any agency thereof, nor any of their employees, make any warranty, express or implied, or assumes any legal liability or responsibility for the accuracy, completeness, or usefulness of any information, apparatus, product, or process disclosed, or represents that its use would not infringe privately owned rights. Reference herein to any specific commercial product, process, or service by trade name, trademark, manufacturer, or otherwise does not necessarily constitute or imply its endorsement, recommendation, or favoring by the United States Government or any agency thereof. The views and opinions of authors expressed herein do not necessarily state or reflect those of the United States Government or any agency thereof. 


\section{DISCLAIMER}

Portions of this document may be illegible in electronic image products. Images are produced from the best available original document. 


\title{
LA-UR- $98-4180$
}

\author{
Explosive Flux Compression: 50 Years of Los Alamos \\ Activities" \\ C. Fowler, D. Thomson, and W. Garn \\ Los Alamos National Laboratory, Los Alamos, NM
}

\begin{abstract}
Los Alamos flux compression activities are surveyed, mainly through references in view of space limitations. However, two plasma physics programs done with Sandia National Laboratory are discussed in more detail.
\end{abstract}

\section{Introduction}

In this section, we briefly outline major Los Alamos (LANL) flux compression activities. More detailed discussions are given of two programs done with Sandia National Laboratories, (SNL) intermittently from 1966 to 1973. Use of flux compression generators (FCG's) to power 6-pinches is discussed in Sect. II. The "Birdseed" program, in which 150-200 kJ of neon plasma was injected into the ionosphere, is discussed in Sect. III, together with plans for a more energetic system. The furst open description of the Los Alamos objectives was published in [1]. Items feanured were the use of the high magnetic fields made at Los Alamos to compress D-T plasmas to make lange neutron bursts, for solid-state investigarions, and to accelerate matter, topics that remain relevant today. Later, unclassified Los Alamos activities were surveyed at the first Megagauss Conference (1965), [2]. The nexr Megagauss Conference took place in 1979 [3]. Other activities berween these conferences included high field solid-state and ișentropic compression experiments. Component development included construction of megavolt transformers and FCG improvements, as with the plate generator. FCG uses as power supplies for railguns, the plastua focus, laser generation, e-bean machines and soft X-ray generators are described in later Megagauss Conference Praceedings, as is the development of high current opening switches. A collaborative flux compression program with Los Alamos and Russian scientists from Arzanas-16 began in 1993, and included Magnetized Target Fusion and high field experiments that have been surveyed in [4] and also reported at MG VII (whose Proceedings are in press). Little of our solid-state work bas appeared in the Megagauss Proceedings. However, surveys appear in $[5,6,7]$. More recent wotk has been done in the "Dirac" shot serie where scientists from the USA and several other countries bave collaborated on high field experiments using Russian MC-1 high field generators and Los Alamos strip generators. Various aspects of this program are treated at this conference and at the preceding MG VII Conference.

\section{Explosive-driven $\Theta$-pinch experiments}

A. Q-pinch liner implosion experiments. Early experiments [2a,c,8] at Los Alamos to apply explosively driven flux compression (MG fields) to high temperanure plasmas were exploratory, and involved creating a fast theta pinch

\footnotetext{
- Work supported by the US Department of Energy.
} 
inside a thin, implodable cylindrical $\theta$-coil. Parameters were chosen to achieve MG fields with systems then available at Los Alanos, and used early $\theta$-pinch data (Scylla I, Scylla III) $[9,10]$. Implosion of the plasma/magnetic system was started using high $T$ high $\beta$ plasma confined by the sxial magnetic field.

In these experiments, a good diagnostic neurron signal verified that the initial plasma was in place as expected, and gave a measure of the plasma behavior vs. time during the explosive driven phase. Fundamental problems existed. Plasma confinement in the short coil $(-25 \mathrm{~cm})$-pinches available for the firing point was limited to 2-3 $\mu \mathrm{sec}$ due to end-loss, flute instabilities $[8,10,11]$ and to field asymmetries [2c]. In 1966, a new $\theta$-pinch (Scyllacita) with a faster capacitor bank was used to create the initial plasma [8]. A new side-fed coil implosion system eliminated field asymmetries. Since the basic plasma confinement time limitation with the short $\theta$-coil $(-3 \mu \mathrm{s})$ remained, as did the quenching effect of the imploding discharge tube, we did not pursue this approach beyond one Scyllacita shot. However, the goal of achieving fusion with MG fields in imploding liners remains valid today. We suggest developing a technique, such as an FRC [12], to inject, at the proper time, an initial high-beta plasma axially into a clean, resistive liner implosion system [2c] for explosive compression to 4 MG or greater. For good confinement, the implosion system length should probably be increased to a half meter or more.

B. The explosive generator powered $\theta$-pinch. In 1967, Los Alamos and Sandia Laboratories collaborated in a series of generator powered $\theta$-pinch experiments using Sandia generators $\{13,14,15,16\}$. Two sizes of heljcal generators were used: the Model 106 generator (S\# of PBX 9404 explosive) and the larger Model 169 (17\# of PBX 9404 explosive). Exploding wire fuses were used to sharpen the pulses to drive the $\theta$-pinch coils. The $\theta$-coils were switched in when the voltage across the fuses reached preselected voltages. The initial plasma was created by first putting a few $\mathrm{kG}$ bias field,- $B_{z}$ in the coil, then passing a linear $z$-current through the deurerium to preionize it, and finally applying the main drive field to heat and compress the plasma.

Nine shots were fired, five with the Model 106 generator and four with the Model 169. Table I of Ref [16] lists conditions for each shot. The preionized plasma was created inside a $2 \mathrm{~mm}$ wall Pyrex or quartz discharge tube with a 40 kA linear current discharge (from a $7.5 \mu \mathrm{F}, 15 \mathrm{kV}$ bank) which was shorted out after a half-cycle to elininate axial current before switching in the generator.

Discharge tube conditioning for each shot involved wanno-up $\theta$-pinch shots with an auxiliary capacitor bank $[14,15,16]$. The generator-powered $\theta$-pinch shot was then fired, complete with preionization, bias field and diagnostics, within 30-60 minutes of the last warm-up shot. Results of the nine generator driven pinch shots are also given in Table 1., [16]. Time rtsolved neutron yields, measuring plasma behavior, have been reported [14,15,16,17]. The shot series denonstrated the importance of reverse bias field, tube conditioning, preionization, and particularly the initial volrage, $V_{\theta}$, applied to the preionized plasma. Good diagnostic neutron yields were obtained on 7 of the 9 shots Results for shots 8 and 9 are shown in Fig 1, which gives the time history of the applied magnetic field $\left(B_{2}\right)$ and the resulting neutron yield rate for each shot. The highest neutron yield $\left(1.4 \times 10^{\mathrm{B}}\right)$ occurred when all drive parameters were at optimum. The maximum neutron yield rate per unit coil length was comparable 
to or beuter than those for laboratory theta pinches worldwide [18]. In 1968, the Frascati group conducted five generator-driven $\theta$-pinch shots with at least one neutron yield ( $5 \times 10^{7}$ ) [19], supporting our demonstration of the feasibility $[, 14,15,16]$ of generator-driven $\Theta$-pinches.

C. Predictions with a $\theta$-pinch scaling model A E-pinch scaling model was developed [20] using a simple computer code and used to calculate plastna radius, temperature, density, neatron yields and radiation rates for a large variety of shon-coil ( $-25 \mathrm{~cm}$ ) Los Alamos 0-pinches (1963-1978), The one-dimensional model assumes thar $V_{\theta}$ drive volage, revese field cancellation, and adiabatic compression may be separated End-losses are neglected for $2 \mu S$. A $\beta=1$ plasma and perfect conductivity are assumed during compression. The code assumes adiabatic compression $\left(T-B^{4}\right)$ and used a radiation loss rate $\sim_{n} n_{1} T_{t}{ }^{12}$ during the compression phase. The code contsined a single scaling constant, $\mathbf{K}$, which successfully correlined rools from Scylla III Scyllacioa and Scylla IA.. It then successfully correlared the ranlts of the 1967 explosive generator shor series.

In the 1970s, a dedicatad then pinch, Scyllar, was used ar Los Alamos to study plasma radiation, opacties, and aromic properties in high temperarure p]asmas-[21,22]. The cote [20] was used to compare Scyllar results at higher densities $\left(-10^{77} / e x\right.$ then used previously $\left(\sim 10^{16} / c c\right)$. Comparisons with experiment were generalky good [20].

In the mid 1970s, high-ameot plare genemators were developed extensively at Los Alamos.[17,23]. These gequerators are fast and can generate multi- MA currents at terawail levels. Using a ypical plate generator performance [17], a calculated [20] freld vs. cume depandence for a 0 -coil $(25.4 \mathrm{~cm} l o \mathrm{gg}, 7.6 \mathrm{~cm} \mathrm{id}$.) is shown in Fig 2. $V_{\mathrm{g}}$ is abour $50 \mathrm{kV}$, and $\mathrm{B}_{2}$ rises from 0 to $900 \mathrm{kO}$ in $2 \mu \mathrm{s}$. With a $50 \mathrm{mT} \mathrm{D}_{2} \mathrm{fill}$, the code predices a fusion (10 keV) neutron yield of $-3 \times 10^{11}$ which could be incresed $20-3 \times 10^{15}$ by using a DT mixture and extending the coil length to one merer. With a fill of 1.0 corr $D_{2}$, seeded with a high $Z$ species, a final temparame of $1.0 \mathrm{keV}$ (Pig, 2) ar a density of $10^{19} \mathrm{~cm}^{3}$ is

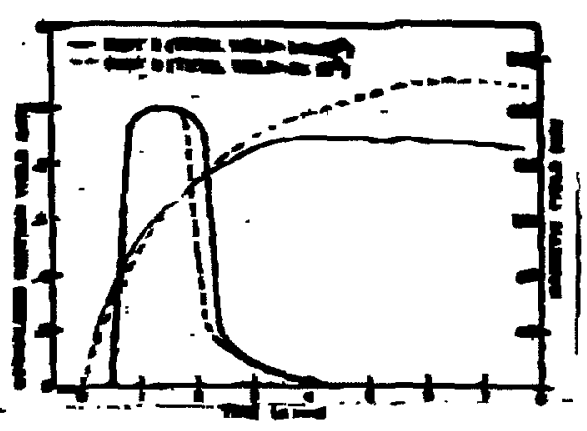

Fig, 1 Megeric field and relaive beruon yield natt va. Bime for two Qpinch shos viling Model 169 generarpr.

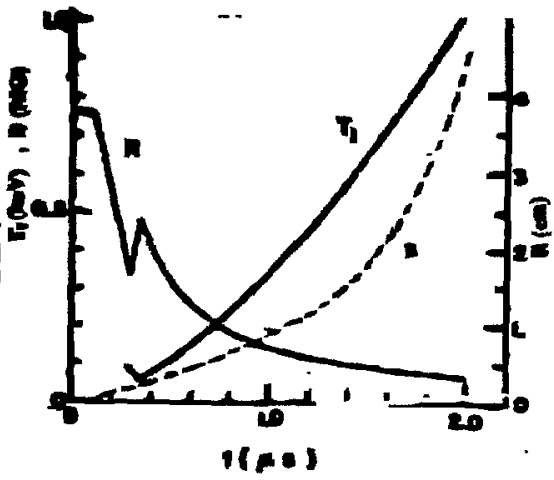

Fis. 2. $B$ vx $t$ in $6 \times 0$ il $(L=25$ mm, id $=7.6 \mathrm{~cm})$ colaulaned from plate generator dam. Plasma emperarur and radius vs $t$ are prodicted tom emperarur end radius ys $t$ are prodicted from
sealing code. $D_{2}$ fill,1.0 tor ; bias feld, 2 Lo 
predicted. If seeded with selected high-Z elements, as with Scylar [21,22], such plasmas would allow studies of atomic processes and opacities at temperatures and densities much higher than those obtained in the laboratory, making possible unique regimes for comparison of spectral observations with theory-

\section{The Birdseed Program}

The initial goal of the Birdseed Program was to inject neon plasma into the ionosphere to study its interaction with ionospheric matter and magnetic frelds. It was hoped that at least $100 \mathrm{~kJ}$ of plasma could be injected, with average directed velocity of $100 \mathrm{~km} / \mathrm{s}$ or greater. Program planning began in 1967 . It was decided that the plasma would be produced by a Marshall plasma gun [24] and that the system would be launched in a Sandia Laboratory STRYPI rocket The gun would be fired when the rocket reached the ionosphere (approximately 220 $240 \mathrm{~km}$ alritude). The STRYPI payload was of order $500 \mathrm{~kg}$. of which somewhat more than $200 \mathrm{~kg}$ were available for the power supply. An FCG system system was selected to power the plasma gun to meet weight and volume restrictions. All system components were designed to be compatible with the planned payload layout and to meet the STRYPI acceleration demands. Figure 3 shows the placement of the major components. These consisred of a capacitor bank, the initial energy source; a Mark V booster generator; the Model 169 output generator; a ballast load and the plasma gun. Switcbing of components into the system was done with detonator closing switches. Neon gas was first injected into the plasma gun from a storage plenum by means of a detonator actuated valve. The capacitor bank ( $-15 \mathrm{~kJ}$, charged mainly during flight by a battery powered DC-DC converter) was fired next to energize the Mark V generator $(-400 \mu \mathrm{H})$, which then delivered 60 to $75 \mathrm{~kJ}$ to the Model 169 generator. This generator was then fired, first into the ballast load B, and subsequently also into the plasma gun. Tests at the Los Alamos Firing Site showed that this system delivered $300-350 \mathrm{~kJ}$ to the gun, with about $60 \%$ of the energy going into the directed plasma Diagnostics showed that for a typical shot, plasma velociries varied from 50 to $250 \mathrm{~km} / \mathrm{s}$, with mean velocities in the range of 90-110 km/s. The program culminated in three successful shots at the Barking Sands Facility in Kauai, Hawaii, two in 1970 (Büdseed D), the third in 1971 (Birdseed II). A summary of the generator-gun development program through Birdseed I can be found in [25], while discussions of the diagnostics employed are available in [26,27]. The system engineering development is treated in [28], and a general description of the STRYPI rocket is given in [29].

Planning for Bindseed III began in late 1970. The system was to be launched in a STRYPI rocket, but was to deliver ten times the plasma energy, thus calling for major changes in the plasma gun and the power supply.

Plasma gun. Birdseed plasma spectra showed appreciable contaminants from gun components which did not appear in lower energy laboratory tests. Consequently, a new gun was designed [30], but not tested, that was expected to generate the required plasma and to withstand the substantially larger required currents. The inner elecrode diameter was increased from 6.35 to $30 \mathrm{~cm}$, the outer electrode diameter from 15.24.to $50 \mathrm{~cm}$ the length from 100 to $150 \mathrm{~cm}$.

Power supplv The power supply was required to deliver a total of about $5 \mathrm{MJ}$, $3.5 \mathrm{MJ}$ to the gun. It would consist of a single, helical generator. Initial flux 


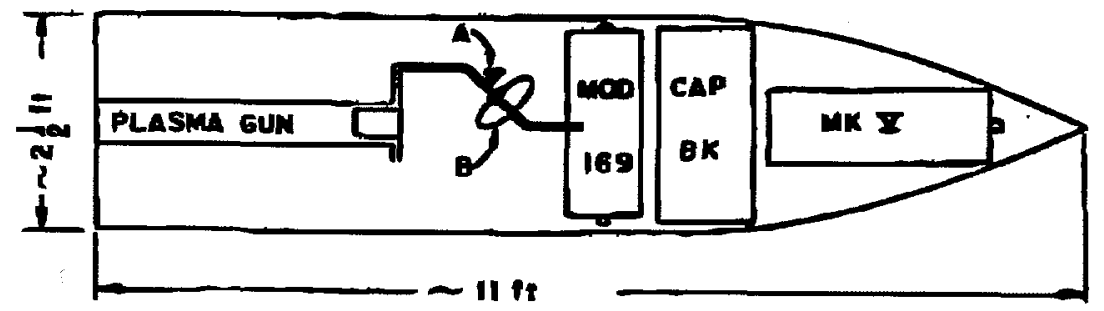

Figure 3. Luation of major sysuen conporems in STRYPI payloud Ballast lasd B carries all the currenl untl plasma gun is switched into circuit by deronawor switch A.

would be supplied by a superconducting coil. A full-scale belical generator was built and tested with satisfactory results, as were acceleration test results on the stator. A NbTi superconducting scaled down coil was built Acceleration tests [31] showed that ir would withstand the rocket accelerations without going normal. The coil was then tested in an explosive shot, where it supplied the initial flux for a scaled down belical generator, writh satisfactory results [32]. There was also some concern that the coil might go normal during launch as the system swept by the steel rocket launch structure. Calculations [33] indicated that a few sheets of magnetic shielding around the coil would solve this problem if it indeed existed

Summary: These experiruents demonstrated the feasibility of using FCG's to power $\theta$-pinclies and plasma guns for physics, fusion and space applications.

Dedication. The authors dedicate this paper to the memory of their colleague and friend, Robert S. (Bob) Caird who passed away on March 27, 1997. Bob was a pioneer in magnetic flux compression, and shared coantborship with us on the first paper published in the Megagauss Conference series.

\section{References $\$$}

1. Alomic Enefor Reverpoh in the Lje and Physieal Sciences, I960, p 104. Available from US Govemantint Printing Offece, Washington 25, DC, 104

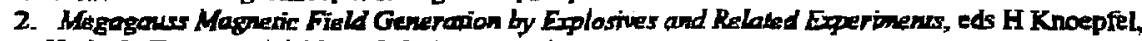
F. Herlach, Euratom, (1960) , 1; b: 101; c; 491

3. Megagunss Physics and Techrolozy, ed P..Turchi, Plenum, NY (1980)

4. I. Lindemuth. C. Erdahl, C. Fowlet, R Reinovsty, S. Youngar, V. Chemyshov, V. Mothorv and A. Pavlousbli, FFE Trans. Flasma Sei., Vol 25, No.6, 1357-1372, (1997)

5. C. M. Fowler, Science 180, 261 (1973)

6. C. Fowler, R Caind, D. Erickson, B. Freemen and w. Garn, in Phystes is High Magnasic Fields, eds S. Chikanumi, N. Muira (Sprüger-Yerlag, New York, 1981), 54-63

7 C. Fowler, B Freeonan, J. Brooks, J.Goenne, W. Hults, J. King, F. Mueller, D. Rickel and J, Smith, Physics B201, 33-39 (1994)

8. D. Thomeon. R Caird, $K$ Ewing. Y. Fidlayson, C. Fowler, W. Gram, E. Kemp, R Kewish, G. Sawyer and J Tuck LANL Reporr LA-3863-MS (1968), (Seyllacita)

9 K Boyer, W. Elmore, E. Liule, W, Quinn J. Tuck, Phys. Rev, 119, 831 (1960),(Soylla D)

10. E. M Little and W. E. Quish, Pbys Fluids 6, 875 (1963). (Scylla III)

11 G. Sawyer, V. Finlayson, F. Jahoda, K. Thomas, Phys Finids 10, 1564 (1967): V.A. Finlayson, LANL Report LA-4042, (1968), (Scylla IA)

12 D. Rej. D. Taggart, M. Baron, R Chrien. R. Gribble, M. Tuszewsld, W. Waganar, B. Wright, 
Phys Fluids B 4 (7), 1909 (1992); S. Aikhanov, V. Balthtin, A, Es'kov, R Kurmullaev, V. Semenoy, E. Surizhov, N. Kodov, V. Khvesyuk V. Yaminskij in Plasma Phys and Caneolled Nucl Fus Resecerch, 1982, (LAEA, Vicnia, 1983, Vol II, 319)

13. J.C. Crawford and R.A Dimeraw, JAP 39,5224 (1968).

14. D. Thomson, R. Caird K.Ewing, C. Fowler, W. Gam, J. Crawford and R Damerow, Proc. of Confi on Puleed High Density Plesma, LANL Report, LA-3770 (1967), Paper H7.

15. R Damerow, J. Crawford, C. Fowler, R. Caird, K. Ewing. W. Gam, D. Thomson, SNL Reporh. SCRR 69-5I (L969),

16. R. Damerow, J, Crawford, D. Thomson, R Caird, K. Ewing, W. Gam, and C. Fowler, in Proc. of Symp on Engirs Problents of Fusion Research, LANL Repor LA-4250, (1969), DI-8.

17. C. Fowler, R. Caird, D. Erickson, B. Freeman, D. Thomson, W. Gam in Erergy Storage, Compr. ,and Swikching, Vol. 2, ods. V. Nandi, H Sahlin, W.Bostick, Plenum Pr ess (1983), 19

18. Sce Table II, Ref [16] and Tablc I, Ref [15]

19. I. Hamm, H. Knoepfit, H. Krogler, I. Linhart and R, Vepbrek, in Proc. Third Conf, on Plasma Phy, and Cantralled Nucledr Fusion Research, Vol. U, (LAEA, Vienna, 1959), 629.

20 K.J. Euring and D.B. Thomson, LANI Report, LA-9074 MS, (1982)

21. D. Thomson, L Jones, A Bailey, and R Englemen, Ir., in Pulsed High Bew Plosmas, D.E. Evens, Erl (Pergamon Press New York, 1976).

22. D. B. Thomson, LANI Report , LA-7684-MS, (1980)

23. R Caird, D. Erickson, W. Gam. and C. Fowler, Proe. IEEE In, Pulsed Power Canj., 1976 (IEEE, N.Y. 1976), Paper III, D-3.

24. J. Mershall and I Henins in Plasma Physies and Controlled Fusian Research, (LAEA. Vicnna, 1966) Vol II, 449-461

25. C. Fowler, D. Thomson. W..Gam, R Caird, LANL Report, LA 5341-MS, (1975).

26. R Caird, C.Fowler, W. Gan, 1, Henins, J. Imgraham, R Jeffies, D. Kerr, J. Marshall and D. Thomson, LANL Report, LA-4302-MS. (1969)

27. D.M Ker and HE. Hansen, LANL Report, LA-4741-MS, (1971).

28. F. Adarns, R. Com, J. May, W. Price and R Seyler, SNL Repor, SC-DR-70-741, (1971).

29. "STRYPI Rocket Systems" SNL Report, SLA-73-0213, (1973)-

30. J, Marshall, LANL Progress Repor, Group P-17, Jan, 1971, 2-5

31. J. D. Ragers, LANL Repor, LA-DC-72-724, (1972).

32 C.Fowler, R.Caird, W.Gern, LANI Rcpor,LA-589a-MS, (1975), 13-14.

33. Private communication, J.D. Rogers, LANL, June, 1998.

We note with sadness the loss of our colleague in the Birdseed program, John Marshall, who passed away on October 21, 1997. 